\title{
O discurso gerencialista e as práticas discursivas das mulheres executivas
}

The managerialist discourse and discursive practices of executive women

\author{
Kelly Pellizari 1 \\ Antônio Carvalho Neto2
}

\begin{abstract}
RESUMO
Este artigo visa analisar as práticas discursivas das mulheres executivas, estabelecendo as relações entre elas e o discurso do gerencialismo. Os resultados da análise indicam que as práticas discursivas das mulheres executivas mais se aproximam do que se distanciam do modelo gerencialista de gestão, uma vez que reforçam a ideologia gerencialista dominante.
\end{abstract}

PALAVRAS-CHAVE: Mulheres Executivas. Discurso Gerencialista; Gerencialismo e Práticas Discursivas.

\begin{abstract}
This article aims to analyze the discursive practices of executive women, establishing the relationships between them and the managerialism. The results of the analysis indicate that the discursive practices of executive women are close to those far from the managerialist management model, since they reinforce the dominant managerialist ideology.
\end{abstract}

KEYWORDS: Executive Women. Managerialist Discourse. Managerialism and Discursive Practices.

\section{Introdução}

O objetivo deste trabalho consiste em analisar as práticas discursivas das mulheres executivas, entendendo estas mulheres como aquelas que se encontram nas posições de liderança e que ocupam os cargos de presidente, vice-presidente e terceiro escalão dentro da hierarquia organizacional das grandes empresas operando no Brasil. Busca-se, com isso, estabelecer as

\footnotetext{
${ }^{1}$ Dra. em Administração, professora adjunta do Curso de Administração da Universidade Federal do Mato Grosso- UFMT/ Brasil. E-mail: kypl_pl@hotmail.com.

2 Dr. em Administração, professor do Programa de pós-graduação em Administração da Pontifícia Universidade Católica de Minas Gerais PUC Minas/ Brasil. Email:carvalhoneto@pucminas.br
} 
relações entre elas e o discurso do gerencialismo. Também se busca estabelecer uma aproximação entre os estudos da área de administração e os da linguística. Para efeitos de estreitamento desta relação, este trabalho contou com a participação de uma pesquisadora nesta área, por se propor a uma rigorosa análise do discurso (AD) com enfoque na linha francesa, uma vez que se pretende entender melhor as práticas discursivas dessas mulheres em meio ao ambiente organizacional. Almeja-se que esta participação auxilie na apropriação que a área da administração tem feito com a AD (SARAIVA et al., 2009).

O termo gerencialismo será utilizado no presente trabalho como a tradução da terminologia managerialism, uma derivação de management em Francês, que é exatamente igual ao termo inglês (GAULEJAC, 2007).

Dentre tantas as possibilidade oferecidas pela análise de discurso, esta pesquisa limitar-se-á a analisar as práticas discursivas das mulheres executivas, bem como utilizará o termo gerencialismo para referir-se ao modelo de gestão baseado no neoliberalismo (CALGARO, 2013). Para efeitos desta pesquisa, o discurso gerencialista diz respeito a todas as práticas discursivas em que se evidencia o gerencialismo como um modelo idealizado de gestão, no qual os gestores sempre devem agir rápida e corretamente para consolidarem-se no poder; uma vez que, tudo que destoe deste objetivo é visto como um empecilho para o sucesso organizacional e do próprio executivo (HECKSCHER, 1996; JONES et al., 2013).

A vida das mulheres executivas pode servir para ilustrar o quanto o discurso gerencialista apresenta-se contraditório àquele ideal proposto. Analisar o discurso destas e contrapô-lo ao discurso gerencialista pode contribuir para conhecermos mais sobre as incongruências do modelo, bem como, expandir o conhecimento acerca destas "mulheres de sucesso", exatamente através do discurso de quem atingiu os cargos mais emblemáticos deste modelo.

Há na literatura trabalhos que pontuam sobre a evolução da mulher no mercado de trabalho, desde o período colonial, passando pela entrada das 
mulheres nas fábricas, pela realidade da dupla jornada de trabalho, acentuada na a partir da década de 1980, e a recente conquista dos altos postos profissionais ocupados por elas (MALUF; KAHHALE, 2010; BARBOSA; ROCHA-COUTINHO, 2012; SANTOS, 2012; MOTA-SANTOS; TANURE: CARVALHO NETO, 2015). No entanto, olhares que buscam compreender as práticas discursivas das mulheres imersas no ambiente organizacional, não são tão facilmente localizados na literatura e configuramse uma lacuna ainda a ser explora, motivando o objeto desta pesquisa.

O interesse pelo tema a ser desenvolvido por este artigo se justifica pela demanda dos estudos no campo da administração em compreender melhor quem de fato é esta mulher executiva que luta para conseguir chegar e se manter nos altos escalões da gestão das grandes organizações brasileiras. A sociedade tem se mostrado mais aberta para dialogar sobre o novo contexto que envolve esta mulher, tanto nas questões sociais, quanto organizacionais (OLIVEIRA; GAIO; BONACIM, 2009).

Este estudo buscou analisar as características das executivas "de sucesso" $_{3}$ em âmbito profissional e também pessoal, buscou-se ainda confrontar seus discursos ao modelo de gestor idealizado pelas organizações atuais, o gerencialismo dominante. Tal proposta mostrou-se relevante, uma vez que traz a tona a discussão a respeito das incongruências do gerencialismo, como modelo idealizado de gestão tecido no contexto organizacional contemporâneo. Deste modo, tendo-se em vista esta complexidade, o problema não deveria recair sobre o sujeito, mas sim sobre o modelo de gestão que não contempla tal complexidade humana.

Para efeitos didáticos este artigo será estruturado em cinco partes. Iniciou-se pela introdução, ora apresentada, seguida do embasamento teórico, posteriormente apresentar-se-ão os procedimentos metodológicos, seguidos

\footnotetext{
${ }^{3}$ Adotar-se-á este termo para se referir às mulheres que se encontram nas posições de liderança e que ocupam os cargos de presidente, vice-presidente e terceiro escalão dentro da hierarquia organizacional das grandes empresas operando no Brasil.
} 
da análise e interpretação dos dados. Para finalizar, algumas reflexões sobre a pesquisa serão marcadas nas considerações finais.

\section{Aporte Teórico}

\subsection{0 discurso do gerencialismo}

A mudança de paradigma na concepção da administração, de meramente instrumental para além dessa instrumentalização, promoveu o cenário investigativo e reflexivo da ciência de administrar e o conduziu à tentativa de compreensão e crítica a um processo denominado "colonização", contra a importação acrítica do modelo de gestão com origem no estrangeiro, mais precisamente os Estados Unidos. Esse processo de "colonização" foi precursor do management ou managerialism, fenômeno que representa um conjunto de políticas e práticas de gestão a serem seguidas, ou seja, uma ideologia gerencialista (WOOD JR et al., 2011; TONELLI, 2013).

Para Calgaro (2013), o termo gerencialismo é originário da administração e é utilizado para designar o modelo de gestão baseado no neoliberalismo. Pollitt (1990) também concebe o gerencialismo como ideologia devido ao fato de considerá-lo como um conjunto de regras e ações que resolveriam todos os problemas de ordem econômica e social.

O discurso do gerencialista ultrapassa as fronteiras práticas da gestão, inserindo-se não apenas no ambiente organizacional como também fora dele, como um conjunto de conhecimentos, valores e comportamentos (FOUCAULT, 1979; GAULEJAC, 2007; DAR; COOKE, 2008; WOOD JR et al., 2011; TONELLI, 2013; BERTERO et al., 2013).

Gaulejac (2007) detecta, no gerencialismo, um sistema de organização de poder. Deste modo, o gerenciamento mostra-se como sinônimo de dominação que conduz o indivíduo a um fim único, a priori, voltado para o capital.

A perspectiva pós-colonialista procura apresentar o fundamento do pensamento norte-americanocêntrico, enraizado na maneira de pensar o mundo de acordo com a supremacia norte-americana, expondo, assim, a falsa 
neutralidade e seu caráter dominador (FOUCAULT, 1979). O póscolonialismo pressupõe a existência de um processo emaranhado de práticas inter-relacionadas que pretende estabelecer a hegemonia ocidental política, econômica, militar, cultural e ideológica (WOOD JR et al., 2011). Desse modo, a ideologia gerencialista configura-se como uma forma de legitimar e disseminar a hegemonia americana, juntamente com o pensamento neoliberal.

O gerencialismo, como salienta Alcadipani (2011), se propõe como a solução para a minimização dos inputs e a maximização dos outputs. O modelo corporativo, permeado pela ideologia gerencial, solidificou-se na contemporaneidade como "a maneira" de se fazer gestão. Isso explicaria a adesão deste modelo também pelas instituições públicas, instaurando-se, também neste setor, a lógica da produtividade do setor privado (ARAÚJO; PEREIRA, 2012). Nesse sentido, toda e qualquer empresa deveria exigir continuamente de funcionários eficiência e eficácia em todos os processos realizados, como se estes fossem máquinas de precisão, da qual defeitos não são admitidos. Essa seria a fórmula mágica para o sucesso organizacional, correta e justa (ALCADIPANI, 2011).

Dessa maneira, é possível perceber que a perspectiva do gerencialismo foi muito além de um simples modelo de gestão, atingindo toda a sociedade com um pensamento imediatista e reducionista, que enaltece o ganho a qualquer custo (FOUCAULT, 1979; GAULEJAC, 2007; ALCADIPANI; BERTERO, 2012).

Esta dificuldade de se pensar em algo genuíno ou ao menos de se questionar o modelo do gerencialismo estende-se não apenas às organizações, mas também à academia. De acordo com Alcadipani e Tureta (2009), buscase romper com a aceitação maciça do modelo hegemônico de gestão, propondo algo mais pluralista.

Gaulejac (2007) enfatiza a inércia dos sujeitos diante do modelo de gestão atual, tido como uma doença social, na medida em que não respeita os limites humanos ao preconizar apenas o gerencialismo e sua busca 
desenfreada por lucros. Tremblay (2005), ao observa a forma com que os gerentes lidam com o trabalho e a família, aborda as particularidades marcadas pelas conhecidas pressões por resultados, flexibilidade dos empregados e a linha tênue que separa a vida pessoal e profissional dos gerentes em meio ao contexto organizacional.

O caráter opressor do gerencialismo entrelaça-se com os anseios da (pós-)modernidade e suas pretensões de controle e ordenação, fazendo com que o sujeito moderno viva em constante mudança, o que acarretaria instabilidade identitária e relações sociais mais superficiais (BAUMAN, 1999; GAULEJAC, 2007). Essas relações sociais não são concebidas pelo modelo idealizado de gestão, uma vez que, nessa concepção, não há espaço para falhas e inadequações. No entanto, elas extrapolam o instituído por manifestarem as incongruências e contradições deste modelo.

O discurso gerencialista parece se disseminar nas organizações pelo discurso dos próprios sujeitos que a compõem e por meio de suas práticas discursivas, talvez por esta razão esteja presente nas entranhas organizacionais e dificilmente seja notado, cotidianamente, como algo a ser questionado ou repensado. Nesse sentido, analisar o discurso das mulheres líderes nas organizações e perceber as relações que se estabelecem entre o gerencialismo e a realidade vivenciada por elas mostra-se pertinente e instigante.

\subsection{A mulher executiva no contexto ideológico do modelo gerencialista}

O fato de a mulher ter buscado romper com as amarras da discriminação, preconceitos e estereótipos por conta do gênero parece não ser o bastante para colocá-la em posição de vanguarda nas empresas (BROADBRIDGE; KERFOOT, 2010; CARRIERI et al., 2013), ela precisa ainda encontrar forças para enfrentar a ideologia do gerencialismo presente nas organizações. Devido a essa questão, as executivas se veem diante de um impasse constante que culmina com incógnitas acerca da conciliação da 
carreira de executiva e vida pessoal, em um ambiente que prioriza uma instância social em detrimento de outra.A busca da mulher pelo reconhecimento igualitário no ambiente organizacional mostra-se velada, assim como também é implícita a discriminação que sofre nesse ambiente ( CAMPO; SILVA, 2013).

O gerencialismo como modelo de gestão ideal das organizações reforça a não aceitação da mulher nos escalões mais altos de liderança, mesmo que implicitamente, ao abordar posturas historicamente atreladas ao masculino, como agressividade, ambição e assertividade como norma geral desejável (GAULEJAC, 2007). Neste sistema, a mulher só pode ser aceita na condição de seguidora, cabendo a ela a posição de liderada.

Neste sentido, Alcadipani e Tureta (2005) afirmam que a figura dos gestores reproduz o discurso e as práticas capitalistas, ao passo que também são alvos destas, sobretudo se o alvo figurar como minoria (mulheres executivas4, negros e homossexuais). Assim, as executivas figurariam em dois extremos na organização: de um lado seriam as propagadoras do gerencialismo, no qual não pode haver falhas e, de outro, seriam acometidas pelos mesmos princípios que disseminam em nome de um projeto ao qual estão submetidas.

No entanto, observa-se que esse modelo traz consigo uma gama de contradições. Essas incoerências podem ser consequência da presença, mesmo que com nova roupagem, do gerencialismo como prática a ser seguida em nome de um objetivo maior, ou seja, a busca da super-lucratividade a todo e qualquer custo.

Ao apresentar as intempéries para a chegada e permanência das executivas no topo organizacional, Carvalho Neto et al. (2010) põem em xeque o discurso gerencialista, uma vez que nele não há lugar para problemas, sobretudo de ordem individual. O ideal gerencialista vê o gestor como

\footnotetext{
${ }^{4}$ Apesar das mulheres serem a maioria em termos populacionais e força de trabalho, elas são minoria nos altos cargos de gestão no Brasil.
} 
replicador do modelo e, assim, mostra-se pouco eficaz em perceber as questões que envolvem a vida pessoal e profissional das executivas, podendo-se perceber conflitos extremos em vários níveis dessas duas instâncias. Tanure e Carvalho Neto. (2007) apontaram o excessivo investimento na carreira, a maternidade, a dedicação à família e ao parceiro amoroso como alguns desses níveis, indicando que as organizações não conseguem controlar tudo e todos de maneira satisfatória, como sugere o modelo idealizado, implícita ou explicitamente. Tonelli (2013) já sinalizava para a vulnerabilidade das relações afetivas em detrimento do trabalho, como elemento central na vida das pessoas.

A ideologia gerencialista, quando contraposta aos desafios que a mulher executiva enfrenta cotidianamente nas organizações, pode ilustrar o quanto o modelo é limitado. Essa limitação pode ser constatada na medida em que o desequilíbrio entre vida pessoal e vida profissional se torna insustentável, requerendo da mulher um esforço quase sobrenatural para enfrentar a realidade que a cerca. A cobrança de responsabilidades recai mais sobre a mulher, que se vê literalmente entre extremos para cumprir seus papéis sociais (CARVALHO NETO et al., 2010; SANDBERG, 2013).

A carreira da executiva é permeada por conflitos e escolhas difíceis. Desse modo, criam-se barreiras e limita-se a ascensão feminina em funções na alta administração, já que "o indivíduo deve consagrar-se inteiramente a seu trabalho, sacrificar tudo pela sua carreira” (GAULEJAC, 2007, p. 120).

No discurso gerencialista, onde tudo deve ser feito com urgência, eficácia e sem que haja "ruídos". O desprezo pelas limitações humanas, para não se referir apenas às mulheres, é evidente, e vem se perpetuando nas organizações cada vez com mais afinco. O gerencialismo promete ao sujeito anular todo e qualquer percalço entre ele e o sucesso, atrasos, falhas, perfeição dos processos e lucros eternos, uma vez que a exigência não tem limites. "O ideal se torna norma" (GAULEJAC, 2007, p. 121).

Se a necessidade, seja ela qual for, configura-se como justificativa para as executivas enfrentarem tantos conflitos, o desejo pela maternidade pode se 
mostrar como um dos maiores empecilhos que elas precisam enfrentar. Para as executivas, a realização da maternidade encontra um dilema quando pensada ou contraposta à carreira (SANDBERG, 2013). O sentimento de culpa que acomete as mães executivas, em razão da falta de tempo para os filhos e afazeres domésticos, é também um fator que merece destaque neste cenário de tensões (CARVALHO NETO et al., 2010). Assim, elas se desdobram para atender aos vários papéis sociais, como ser profissional, ser mãe, ser gestora do lar e ainda esposa (CARVALHO NETO et al., 2010).

Esse cenário só mudará na medida em que as organizações compreenderem que sua finalidade não é exclusivamente econômica e financeira, como a ideologia do modelo gerencialista dissemina, mas também humana e social. Aí talvez estes percalços sejam minimizados. Nesse contexto, Gaulejac defende a ideia de que só haverá emancipação do modelo gerencialista quando a gestão trouxer um sentido mais nobre ao ser humano, que não apenas aquele focado no ter. "Uma gestão mais humana, que recuse instrumentalizar os homens, considerando-os como um custo ou como um recurso" (GAULEJAC, 2007, p. 289).

As pessoas ainda são vistas essencialmente como "objetos descartáveis" pelas organizações, e o gerencialismo só reafirma essa constatação. Por esta razão, acredita-se que a gestão nos moldes atuais se encontra em processo de ampliação de suas influências para todas as esferas da vida humana. A figura da mulher executiva e todos os seus dilemas inerentes à vida profissional pode bem representar o quanto o modelo é desajustado. O gerencialismo como padrão de gestão apresenta um fim em si mesmo, gerando paradoxos que o modelo não consegue redimensionar e tampouco compreender (GAULEJAC, 2007). Nesse contexto, o discurso das executivas apresenta-se conflituoso,

repleto de dilemas e amplamente ambíguo (MENEZES, 2012; CARRIERI et al., 2013).

\section{Metodologia}

\subsection{Estratégia e métodos de pesquisa}


A opção pela abordagem qualitativa desta pesquisa se deve ao fato de que é difícil pensar em discurso pelo viés quantitativo, e por compreender que a perspectiva qualitativa pode contribuir com mais eficácia para com os objetivos a que se propõe esta pesquisa, já que por meio dela observa-se além do caso, seu contexto (GIBBS, 2009).

O método escolhido para analisar o discurso das executivas, estabelecendo nele as relações entre elas e o modelo gerencialista, no que tange às suas vidas profissionais e pessoais foi o estudo de caso, tal qual concebido por Miles e Huberman (1994). O estudo de caso "é aplicado muitas vezes nos estudos organizacionais para descrever qualquer pesquisa baseada em um único caso, como uma empresa, um grupo ou departamento" (MARIZ et al., 2005, p. 6).

Esta pesquisa foi formulada com base em dados secundários. Determinou-se a seleção de respondentes em um banco de dados já estruturado e reconhecido por fornecer dados sobre mulheres executivas. Assim, percebe-se que a base utilizada tinha potencial para fornecer dados que ajudariam a compreender o objeto de análise. Desta forma, em um primeiro momento, foram coletadas 50 entrevistas semiestruturadas e já transcritas com mulheres executivas presidentes, vice-presidentes, diretoras ou superintendentes de grandes empresas que atuam no mercado brasileiro em diferentes regiões do país. Essas entrevistas foram realizadas entre junho de 2010 e junho de 2011 fora do ambiente de trabalho. Para efeitos de realização desta pesquisa, foram selecionadas 13 das entrevistadas em um universo de 50. Dentre essas, havia executivas que ocupavam diferentes cargos integrantes do terceiro escalão, e atuavam em diversos setores da economia.

A seleção das entrevistas utilizadas obedeceu a alguns critérios previamente estabelecidos. Foram observados tópicos, como a idade das entrevistadas, que compreenderam participantes entre 30 e 45 anos; com relação afetiva de caráter estável; além da opção por executivas que possuem filhos, ainda que este grupo não represente o perfil de executivas de alto 
escalão, ancorado pela literatura majoritária, ele pode trazer contribuições significativas para a área de pesquisa. Estes critérios de seleção foram adotados visando uma maior homogeneidade entre as respondentes.

\subsection{Estratégia de análise: $\mathrm{AD}$}

A análise dos fragmentos das entrevistas foi realizada por meio da $\mathrm{AD}$, pelo viés francês, por julgar ser esta perspectiva a que tem maior possibilidade de ilustrar o modelo empírico escolhido para compor a pesquisa. Os precursores desta vertente são Pêcheux (1990), Maingueneau (2005) e, no Brasil, Orlandi (2002, 2005, 2007). A escolha da abordagem francesa para tratar os discursos, se dá em razão da proposta deste artigo que visa compreender melhor as práticas discursivas das mulheres executivas imersas no contexto organizacional, que evidencia o discurso gerencialista, e não apenas levantar uma crítica a tal modelo. Entende-se que esta visão mais interpretativista do objeto, inscreve-se na concepção francesa da AD.

As entrevistas das executivas, constituindo-se a materialidade discursiva a ser analisada. Na concepção adotada por Pêcheux, para compreender o discurso parte-se da materialidade, por entender que a partir dela emergem os discursos e seus sentidos. Assim, cabe ao analista de discurso fazer uma análise não subjetiva da subjetividade encontrada na materialidade das entrevistas (ORLANDI, 2005).

$\mathrm{O}$ conceito de $\mathrm{AD}$ foi se modificando ao longo dos tempos, assim como a noção de discurso foi ganhando novos contornos na medida em que os estudos na área foram se desenvolvendo. Desse modo, Mussalim (2001) ilustra que a $\mathrm{AD}$ passa por três fases, denominada $\mathrm{AD}-1, \mathrm{AD}-2$ e $\mathrm{AD}-3$.

Na AD-1, também conhecida como análise automática do discurso (AAD), os discursos são menos instáveis que nas fases seguintes, gerados pela lógica da "máquina discursiva", proposta por Pêcheux (1990). Na AD-2 a noção de "máquina discursiva" já não se sustenta mais, pois o conceito de formação discursiva (FD) proposto por Foucault (1979) entra em cena. Já AD3 adota a perspectiva de que os discursos presentes nas FDs são interligados 
de modo a formarem uma relação interdiscursiva, que pode ser entendida, grosso modo, como um discurso que se relaciona com outro discurso e constituem um novo. Para Mussalim (2001, p. 120) "será a relação interdiscursiva que estruturará a identidades das FDs”. Maingueneau (1997) afirma que apenas na $\mathrm{AD}-3$ é que ocorre a desconstrução da "máquina discursiva", pois nesta etapa há um deslocamento entre o que diz respeito à relação de uma FD e outra. Conforme ora exposto, pode-se observar que o conceito de FD tomado de empréstimo de Foucault (1979) é apresentado nas fases AD-2 e AD-3, por esta razão elas serão foco da análise deste trabalho.

\section{A análise dos Dados}

\subsection{0 discurso gerencialista}

Uma das questões mais recorrentes nas entrevistas selecionadas para esta análise diz respeito ao fator econômico que o modelo gerencialista proporciona a seus integrantes, sobretudo aqueles que se dispõe a atender seus interesses. Como se pode observar nos recortes a seguir, o dinheiro é eleito como mola propulsora do gerencialismo.

"É, você tem que dar conta, cê tem que ter dinheiro, cê tem que trabalhar... sem dinheiro a gente num faz nada... né".

"É ter meu próprio dinheiro. Independência financeira...".(E 1, grifos da autora).

O recorte acima apresentado foi extraído das entrevistas selecionadas. Ao serem indagadas quanto ao fator mais relevante para sua chegada ao alto escalão na hierarquia organizacional, as executivas apresentaram discursos diversos. Pode-se perceber o discurso gerencialista explicitamente, pois são carregados dos interesses exaltados pelo gerencialismo. As formulações "independência financeira", "trabalho" e "poder sobre todas as coisas", são questões recorrentes em todo o discurso gerencialista (GAULEJAC, 2007) e propagadas pelas práticas discursivas das executivas (ORLANDI, 2005). Em "tem que ter dinheiro", "tem que trabalhar" se estabelece a relação 
"dinheiro/trabalho" que mantém e constitui as relações de trabalho na contemporaneidade em um modelo capitalista.

Portanto, as formulações dinheiro e trabalho estabelecem uma relação de alternância. Assim, a necessidade de se ter dinheiro equivale à necessidade de se ter trabalho. O sentido de trabalho é constitutivo de uma memória capitalista em que o dinheiro é visto o elemento mais importante, do qual não se pode abdicar. $\mathrm{O}$ dinheiro é basicamente a moeda de troca, para as relações que se estabelecem pelo gerencialismo. Desta forma, o trabalho apenas serve para sustentar a possibilidade da estabilidade financeira do sujeito.

As relações de força e poder também são questões recorrentes no discurso gerencialista. Dentro deste contexto podem ser entendidas como "uma tensão entre diferentes sentidos" (FEDATTO; MACHADO, 2007, p. 9). O gerencialismo também se configura como uma ideologia sustentada nas relações de poder que se estabelecem no ambiente organizacional (THOMPSON, 1995).

Nesta perspectiva busca-se analisar os recortes que se seguem:

“(...) às vezes... eu falo 'ah, nem sei se eu queria ser tanto', porque aí vai ficando mais pesado, vai dando trabalho, mas aí a gente fala que é meio que um vício também, a coisa vai, no fim você tá lá, você continua trabalhando, quer continuar dando resultado (...)”. (E 12, grifos da autora).

No discurso gerencialista, o poder também está relacionado ao trabalho, de modo que, quanto mais o sujeito trabalhe mais chances ele tem de chegar ao poder. O trabalho se mostra neste contexto como uma ponte para que se atinja o objetivo final que é o poder, uma vez que este poder garantiria aquilo que o gerencialismo evidencia a todo custo, o dinheiro. Pode-se dizer, por esta razão que o discurso gerencialista, assim como o próprio gerencialismo é um modelo cíclico, em que o trabalho leva ao poder e o poder ao dinheiro que por sua vez exige do sujeito uma contrapartida sempre maior. (GAULEJAC, 2007). 
Ao se considerar que a ideologia muda conforme a materialidade do espaço pode-se compreender a razão delas tecerem enunciados que contenham elementos que sejam reverenciados pelo gerencialismo, já que as mulheres enunciam de um mesmo lugar ideológico. Pode-se compreender esses enunciados, partindo-se da premissa de que a ideologia tem existência material e que essa prática material reproduz as relações de produção, deste modo, a ideologia funciona de maneira à assujeitar o indivíduo, tornando-o um sujeito ideológico (inconscientemente ele imagina ser o senhor de sua vontade), quando na verdade, esse assujeitamento faz com que ele ocupe um determinado lugar, um determinado discurso em dada formação social. (ORLANDI, 2001; OLIVEIRA, 2007). Assim, fica mais fácil compreender porque o discurso das executivas parece sobrepor-se.

Essa ideologia é tão marcante nas organizações que pode ser percebida nos discursos das mulheres nos mais diversos níveis hierárquicos, sobretudo nos elevados. Seguem-se os recortes.

“(...) eu controlava todo serviço terceirizado; eu não tenho dificuldade de dar ordem, de me impor, de falar o que eu penso. Então eu ach... se você me perguntar eu me acho meio homem, assim eu... eu não sou mulherzinha."

"(...) eu tenho dois apelidos, um é trator."

"É pedir a Deus pra nascer homem”. (E 2, grifos da autora).

A valorização da caracterização masculina é evidenciada no discurso gerencialista pelo gênero feminino, como no discurso na posição de mulher executiva e propagado pelas suas práticas discursivas. Pode-se constatar tal situação no seguinte recorte, "eu não tenho dificuldade de dar ordem, de me impor", a própria executiva (mulher) acredita que "dar ordens" seria uma atribuição apenas masculina, ou seja, ela caracteriza isso como pertinentes ao sexo masculino. $\mathrm{O}$ fragmento demonstra uma das ações comuns realizadas pelos gestores, dar ordens, mas o trecho que segue "de me impor" pode ilustrar o quanto a delegação de ordens faz referência direta ao poder e imposição da 
vontade de um líder, o que é típico do ideal gerencialista, (GAULEJAC, 2007). Quando o sujeito precisa impor-se, tem-se a situação da não aceitação ou resistência, pois do contrário a relação seria outra. A imposição remete-se ao exercício da força, característica atrelada à figura masculina, que não necessariamente precisa ser ocupada por um homem, mas por uma pessoa que se reconheça como tal.

Em "eu me acho meio homem", pode-se perceber o discurso de um sujeito que se reconhece no outro, e toma o discurso do outro como seu. Assim, a mulher ao galgar posições de chefia no modelo gerencialista tende a assumir posturas e características masculinas esperadas do cargo de gestão. Esse processo se dá pela aceitação e reconhecimento de uma ideologia pelo sujeito, ou de forma inconsciente, quando o sujeito imerso neste sistema não percebe a lógica a qual lhe é imposta. (MUSSALIM, 2001). A ideologia se faz presente muito antes do sujeito se perceber como indivíduo, ela é interiorizada e disseminada como se fosse uma verdade absoluta, como um valor a ser replicado, e em dado contexto não é facilmente percebida como algo culturalmente criado e que por esta razão poderia ser diferente.

Deste modo, as mulheres ingressam no meio organizacional, tendo que lutar contra uma ideologia patriarcal fortemente enraizada. Essa formação ideológica exerce força coercitiva sob as formações discursivas das executivas, dessa maneira muitas executivas incorporam e passam a disseminar esse modelo de gestão com naturalidade, uma vez que neste contexto os enunciados já estão preestabelecidos como no fragmento "eu tenho dois apelidos, um é trator". Nota-se neste discurso que a mulher mais do que comparação com o gênero masculino, busca incorporar características que o modelo julga como necessárias para que se consiga êxito. Ao expor que é conhecida no ambiente de trabalho como um trator, cujos sentidos podem ser os mais variados possíveis, tanto positivos (uma máquina para trabalhar) quanto negativos (atropela das pessoas), recaem sobre ela todas os estereótipos marcados pelo gerencialismo e que podem estabelecer relações com a figura a ela associada. O fato de a executiva expor essa questão pode ilustrar que ela não se incomoda 
ao ser comparada com um trator, o que pode ser comprovado e melhor entendido, quando esta mesma mulher, evidencia seu desejo em nascer homem, expresso quando indagada sobre seu poder de escolha em relação à outra vida, “É pedir a Deus pra nascer homem”.

\subsection{As práticas discursivas das executivas}

As executivas parecem estabelecer relações conflituosas com a ideologia gerencialista, no entanto, não se trata aqui de identificar ou avaliar à qual ideologia elas devam seguir, o que se busca apresentar é que estas executivas também demonstram ter práticas discursivas que destoam dos pressupostos pautados pelo gerencialismo, ao deixar transparecem em seus discursos, elementos como fragilidade, culpa e escassez de tempo para atividades fora do trabalho, dentre outros elencados.

Seja pela contradição ao modelo, por resistência ou inconscientemente, os discursos elaborados pelas executivas e apresentados neste momento se afastam aparentemente da retórica daqueles mencionados na sessão anterior, conforme se pode constatar nos recortes que seguem:

“(...) nas etapas do meu crescimento profissional... têm nisso... as suas dores, um processo de crescimento dolorido digamos assim, com a dor do crescimento, então nem sempre dependendo da sociedade que a gente se encontra e, não tem o caminho totalmente aberto." (E 9, grifos da autora).

Apesar de o preço que se paga para manter ou disseminar essa ideologia gerencialista, por vezes passa despercebido no cotidiano dos executivos em geral, mesmo neste contexto têm-se enunciados como o que segue, "nas etapas do meu crescimento profissional... têm nisso... as suas dores". O discurso que se apresenta no fragmento pode ilustrar as fragilidades do modelo idealizado de gestão, uma vez que a busca contínua pelo trabalho, aprimoramento, poder e dinheiro nunca acontece de modo natural, ou seja, parece acontecer á duras penas, como se pode observar no discurso anteriormente apresentado. É interessante notar que a mesma 
executiva (E 9) que menciona trabalhar por realização, (embora a lógica desta realização, como já analisado, se dá em nome do fator econômico) é quem demonstra sua fragilidade frente às pressões exercidas pelo gerencialismo, conforme materializa em seu próprio discurso "com a dor do crescimento". Neste enunciado pode-se perceber a situação de assujeitamento da qual já se mencionou anteriormente. No enunciado da executiva ela afirma que trabalha pela realização, enquanto na verdade, ideologicamente assujeitada, o trabalho visa atender aos fins ideológicos preestabelecidos. Seu outro enunciado, afirmando a dor pelo exercício do trabalho (cobrado pela ideologia) surge como um elemento de resistência frente a esta ideologia. Esta resistência pensada diferentemente de oposição ao gerencialismo, mas como adequação de sua própria condição de mulher executiva (ORLANDI, 2001).

Ao reconhecer que o processo de chegada e permanência da mulher ao poder nas organizações se dá de maneira árdua percebe-se a incompatibilidade de modelo para com o sujeito que o incorpora, pois parece incoerente o sujeito desejar algo para si que o faça sofrer, adoecer ou prejudicá-lo de alguma maneira.

O discurso gerencialista também parece perder a noção de tempo e de da exaustão humana, por não considerar que haja o tempo do não trabalho, em sua lógica, o modelo atua e solicita do indivíduo dedicação contínua, vinte e quatro horas por dia, sete dias na semana e assim sucessivamente, de modo que, quanto mais o indivíduo se dedica, maior dedicação se demanda a à ele (GAULEJAC, 2007; ALCADIPANI, 2011; TONELLI, 2013). O fragmento que segue pode bem ilustrar essa questão.

"Na verdade, assim, como eu, eu não posso me desligar, porque, o meu trabalho, a minha responsabilidade é com a operação da empresa, então é 24 por 7 . Porque na área da tecnologia da informação, você trabalha 24 por 7 , porque tem, o ambiente, a infraestrutura de tecnologia ela tem que estar disponível o tempo todo." (E 7. Grifos da autora). 
Em "eu não posso me desligar, porque, o meu trabalho, a minha responsabilidade é com a operação da empresa, então é 24 por 7", a dimensão de tempo dedicado à empresa parece não ter fim, na formulação "eu não posso me desligar", indica a dedicação contínua ao trabalho, mesmo que o sujeito não esteja nas nos espaços delimitados pela organização ele se vê constantemente trabalhando já que as cobranças podem vir a qualquer hora do dia ou da noite. Isso se tornou possível com o advento da tecnologia do qual a ideologia gerencialista soube apropriar-se perfeitamente, dessa maneira, ela incute no indivíduo a necessidade de doação extrema e por meio dos aparatos tecnológicos promove uma aproximação maior entre a empresa e o empregado, esta ligação estreita entre o trabalhador e o trabalho, faz com que, um não se reconhece sem o outro (BAUMAN, 1999). No fragmento acima essa relação é marcada pelas formulações "meu trabalho, minha responsabilidade", reforçada pela "você trabalha 24 por 7", em que se trabalha o dia todo, o tempo todo, "não pode se desligar". Essa exigência sem fim fomentada pelo trabalho corrobora com as questões já levantadas por Tonelli, (2013). No entanto, apesar de auferirem estruturas que funcionem como extensões de si próprias, as executivas parecem transitar no espaço conflituoso entre as relações pessoais e profissionais, de modo a travarem embates eternos e sentimentos como os que se apresentam no seguinte recorte.

"Sentimento de culpa: A... demais. Eu acho que meu filho inclusive eu faço muita coisa errada pra compensar".

"Hoje quando eu olho uma criança ao meu lado, eu falo meu Deus eu não lembro desta fase do meu filho. E ai você olha pra isso com muita culpa.(E 8, grifos da autora).

O sentimento de culpa por priorizar a carreira ao invés da família, acomete muitas executivas, sobretudo quando a questão diz respeito aos filhos. O recorte "Sentimento de culpa: A... demais", é bastante ilustrativo neste sentido, a culpa que a executiva demonstra pode produzir um efeito de 
sentido do qual o gerencialismo se abstém, ao não contemplar a mulher em sua integridade, ou seja, como detentora de outros papéis sociais que exigem dela a mesma dedicação que o modelo de gestão a solicita. Como a formação ideológica provoca coerção sobre o sujeito, elas abdicam até mesmo dos filhos em nome da carreira e isso lhes causa certo desconforto, materializado pelo elemento culpa, ou dito de outro modo, ilustrado pelo sentimento de culpa da mãe.

Neste sentido a executiva parece punir-se, culpando-se por sua ausência junto ao filho, o que fica evidente no fragmento "Hoje quando eu olho uma criança ao meu lado, eu falo meu Deus, eu não lembro desta fase do meu filho.", aqui a executiva revela a maneira com que a sociedade a cobra em relação ao filho, pois, aos ver outra criança ela se recorda de daquilo que ela não teve, não vivenciou. Esse sentimento de falta pelas experiências não vivenciadas aguça ainda mais a culpa da executiva que se martiriza constantemente, uma vez que ela não encontra mecanismos que a façam perdoar-se por ter priorizado a carreira ao invés do filho. Assim, ela busca artifícios para atenuar ou justificar sua "falta enquanto mãe" (falta esta cobrada pela perspectiva do patriarcado), o que se mostra ineficiente já que seu discurso é claro "aí você olha pra isso com muita culpa".

\section{Considerações finais}

Ao longo deste trabalho buscou-se enfatizar as relações que se estabelecem entre as práticas discursivas das mulheres executivas das maiores e melhores empresas brasileiras e o modelo gerencialista de gestão. As relações presentes neste contexto, muitas vezes, não se dão modo fácil, elas são cercadas de inúmeros conflitos e permeadas por discursos diversificados que ora se aproximam e ora se distanciam entre si, demandando uma análise mais minuciosa para que se possa afirmar mais precisamente as distorções e confirmações.

O discurso gerencialista disseminado pelas organizações e fundamentado nos ideais do gerencialismo estabelece relações de força para com as 
executivas, uma vez que, a ideologia apresentada por este modelo conduz as ações dos sujeitos ligados a ela. No entanto, as práticas discursivas das executivas brasileiras revelam outra conjuntura que, por vezes, destoam daquelas apregoadas pelo gerencialismo.

O discurso das executivas não é claro na medida em que proporcionam efeitos de sentidos diversos, pois apresentam elementos dos quais o gerencialismo não reconhece, como a fragilidade, a culpa e a escassez de tempo para atividades fora do trabalho, a supremacia do sexo masculino em relação ao feminino nas diferentes esferas sociais, como nas organizações, o assujeitamento do sujeito frente a ideologia gerencialista, apenas para citar alguns

As práticas discursivas das executivas apresentam marcas discursivas que reforçam a ideologia gerencialista, mas não se limitam apenas a ela. Por meio da análise das entrevistas pode se observar duas questões: primeiro, que há um esforço grandioso por parte da mulher executiva para que ela consiga disseminar a ideologia gerencialista e manter-se nos postos mais cobiçados de gestão. Segundo, que as práticas discursivas das executivas sinalizam discursos, ora mais, ora menos explícito, em que a executiva clama por socorro diante da ideologia gerencialista.

Com todas as questões suscitadas até o momento, pode-se constatar que as práticas discursivas das executivas mais se aproximam do discurso gerencialista do que se distanciam. No entanto, também fica evidente que existem elementos contrários e incongruentes nas práticas discursivas das executivas em relação ao discurso gerencialista que fazem com que o modelo de gestão seja questionado, no sentido de reconhecer a mulher em sua integridade, e não apenas como um sujeito tentando se ajustar a um molde pré-estabelecido.

Espera-se que as considerações tecidas por este trabalho possam contribuir de alguma forma, no sentido de promover uma reflexão sobre novas posturas diante do modelo gerencialista e até que ponto estas atitudes podem trazer benefícios não só á organização, mas aos sujeitos que a ela pertencem. 
Ao refletir sobre esses posicionamentos, pode-se então pensar em futuras pesquisas que tragam à baila, análises de outros sujeitos imersos na ideologia gerencilista e suas práticas discursivas.

\section{Referências}

ALCADIPANI, R.; TURETA, C.. Perspectivas críticas no Brasil: entre a "verdadeira crítica” eo dia a dia. Cadernos Ebape. Br, v. 7, n. 3, p. 504-508, 2009.

ALCADIPANI, R. ; ROSA, A. R. From grobal management to glocal management: Latin American perspectives as a counter-dominant management epistemology. Canadian Journal of Administrative Sciences/Revue Canadienne des Sciences de l'Administration, v. 28, n. 4, p. 453-466, 2011.

ALCADIPANI, R. Academia ea fábrica de sardinhas. Organizações \& Sociedade, v. 18, n. 57, p. 345-348, 2011.

ALCADIPANI, R.; ROSA, A. R.. "Pós-colonialismo". Revista de Administração de Empresas, v.51, n.6, p. 612-612, 2011.

ALCADIPANI, R.; BERTERO, C. O. Guerra Fria e ensino do management no Brasil: o caso da Revista de Administração de Empresas. FGV-EAESP. 2012.

ARAÚJO, P. G.; PEREIRA, J. R. Análise da aplicabilidade do modelo gerencial na administração municipal. Revista de Administração Pública, v. 46, n. 5, p. 1179 1199, 2012.

BAUMAN, Z. Modernidade e ambivalência, trad. Marcus Penchel. Rio de Janeiro: Jorge Zahar, 1999.

BARBOSA, P. Z.; ROCHA-COUTINHO, M. L. Ser mulher hoje: a visão de mulheres que não desejam ter filhos. Psicologia \& Sociedade, v. 24, n. 3, p. 577-587, 2012.

BERTERO, C. O. et al. Os desafios da produção de conhecimento em administração no Brasil. 2013. 
ROADBRIDGE, A.; KERFOOT, D. Mulheres e homens em gestão: questões para o século XXI. Gênero, Trabalho e Organização , v. 17, n. 5, p. 475-480, 2010.

CARVALHO NETO, A. M.; TANURE, B.; ANDRADE, J.. Executivos: carreira, maternidade, amores e preconceitos. RAE-eletrônica, v. 9, n. 1, 2010.

CALGARO, J.C. C.. Gerencialismo. In: Dicionário crítico de gestão e psicodinâmica do trabalho. In: VIEIRA, Fernando de Oliveira; MENDES, Ana Magnólia; MERLO, Alvaro R. Crespo. Dicionário crítico de gestão e psicodinâmica do trabalho. Curitiba: Juruá, p. 278, 2013.

CAMPOS, F.; SILVA, M. O. Mulheres empreendedoras: O desafio de empreender. Contribuciones a las Ciencias Sociales, 2013. Disponível em http://www.eumed.net/rev/cccss/24/familia-trabalho.html. Acessado em 09.09.2017. DAR, S.; COOKE, B. The new development management: critiquing the dual modernization. Zed Books Ltd., 2013.

CARRIERI, Alexandre de Pádua et al. Gender and work: representations of femininities and masculinities in the view of women Brazilian executives. BARBrazilian Administration Review, v. 10, n. 3, p. 281-303, 2013.

FEDATTO, C. P.; MACHADO, C. P. O muro, o pátio e o coral ou os sentidos no/do professor. Discurso e ensino: o cinema na escola. Campinas, SP: Mercado de Letras, p. 9-15, 2007.

FOUCAULT, M.. Nascimento da biopolítica: Curso dado no Collège de France (19781979), Trad. Eduardo Brandão; Vera Claudia Berliner: Martins Fontes, 1979, 2008.

GAULEJAC, V. Gestão como doença social. São Paulo: Ideias e letras, 2007.

HECKSCHER, C. The New Unionism: Employee Involvement in the Changing Corporation with a New Introduction. Cornell University Press, 1996. 
JONES, J. P; ROBERTS, S. M.; FROEHLING, O.. Managerialism in motion: Lessons from Oaxaca. Journal of Latin American Studies, v. 43, n. 4, p. 633-662, 2011.

MAINGUENEAU, D. Novas tendências em análise do discurso. ed. 3. Campinas: Pontes editora da Unicamp, 1997.

MALUF, V. D.; KAHHALE, E. S.P. Mulher, trabalho e maternidade: uma visão contemporânea. Polêmica, v. 9, n. 3, p. 170-180, 2010.

MARIZ, L. A. et al. O reinado dos estudos de caso na teoria das organizações: imprecisões e alternativas. Cadernos Ebape. br, v. 3, n. 2, p. 01-14, 2005.

MARTINS, S. O. Análise do discurso. RCA-Revista Científica da Ajes, v.2, n. 3, 2015.

MENEZES, R. S. S. Feminilidades em primeira pessoa: narrativas plurais, vivências singulares de mulheres nos negócios. Tese de Doutorado. Universidade Federal de Minas Gerais - UFMG. Belo Horizonte, 2012.

MILES, M. B. et al. Qualitative data analysis: An expanded sourcebook. Thousand Oaks: Sage Publications, 1994.

MUSSALIM, F. Análise do discurso. Introdução à linguística: domínios e fronteiras, v. 2 , n. 2 , p. 101-142, 2001.

MOTA-SANTOS, C. M., TANURE, B.; CARVALHO NETO, A. (2015). O percurso do trabalho feminino no Brasil: vestígios dos primórdios no presente. In.: Andrade, J. O., Carvalho Neto, A. Mulheres profissionais e suas carreiras sem censura. São Paulo: Editora Atlas, 2015.

OLIVEIRA, T. P. Divisão territorial: uma análise discursiva do confronto "não dividir x criar". Tese de doutorado. Instituto de estudos da linguagem - IEL. Universidade Estadual de Campinas. Campinas, SP. 2007. 
OLIVEIRA, A. R.; GAIO, L. E.; BONACIM, C. A. G.. Relações de gênero e ascensão feminina no ambiente organizacional: um ensaio teórico. Revista de Administração da Universidade Federal de Santa Maria, v. 2, n. 1, p. 80-97, 2009.

ORLANDI, E. P.. Discurso e texto: formulação e circulação dos sentidos. Campinas/SP: Pontes, 2001.

ORLANDI, E. P. A análise de discurso e seus entremeios: notas para a sua história no Brasil. Caderno de Estudos Lingüísticos (42), Campinas: Jan./Jun., 2002.

ORLANDI. E. P. "Michel Pêcheux e a análise de discurso. Estudos da língua(gem). Congresso Vitória da Conquista”, Anais. 1, 9-13, Disponível em: $<$ http://www.cpelin.org/estudosdalinguagem/n1jun2005/artigos/orlandi.pdf.> Acesso em: 01 out. 2017.

ORLANDI, E. Análise de discurso: princípios e procedimentos. Campinas, SP: Pontes, 2007.

POLLITT, C.Managerialism and the public services: The Anglo-American experience. Blackwell, 1990.

PÊCHEUX, M. Análise automática do discurso. Por uma análise automática do discurso: uma introdução à obra de Michel Pêcheux, v. 3, p. 61-105, 1990.

PÊCHEUX, M.. O discurso: estrutura ou acontecimento. Campinas: Pontes, 1997.

SARAIVA, L. A. et al. Introdução. Estudos organizacionais e análise do discurso: aproximações possíveis. Análise do discurso em estudos organizacionais. Curitiba: Juruá, p. 11-19, 2009.

SANDBERG, S. Faça acontecer: mulheres, trabalho e a vontade de liderar. Editora Companhia das Letras, 2013. 
SANTOS, C. M. M. As mulheres brasileiras: do espaço privado da casa para as posições executivas nas organizações brasileiras. Tese. Pontifícia Universidade Católica de MG, Belo Horizonte, 2012.

TANURE, B.; CARVALHO NETO, A. Executivos: sucesso e infelicidade. Elsevier Brasil, 2007.

TONELLI, M. J. Organizações, relações familiares e amorosas. In: Eduardo Davel; Sylvia Constant Vergara. (Org.). Gestão com pessoas e subjetividade. 6. ed. São Paulo/SP: Atlas, 2013.

THOMPSON, J. Ideologia e Moderna Cultura: Teoria Social Critica na Era dos Meios de Comunicação de Massa. Petrópolis: Vozes, 1995.

TREMBLAY, D. Gerentes e a conciliação entre trabalho e família. In: Eduardo Davel e Marlene Catarina Melo (org.). Gerência em Ação. Rio de Janeiro: FGV Editora, 2005.

WOOD JR, T. TONELLI, M. J; COOKE, B. Colonização e neocolonização da gestão de recursos humanos no Brasil (1950-2010). RAE-Revista de Administração de Empresas, v. 51, n. 3, p. 232-243, 2011.

Recebido em setembro de 2019. Aprovadoem dezembro de 2019. 